\title{
Fluorouracil/Mitomycin Regimen
}

National Cancer Institute

\section{Source}

National Cancer Institute. Fluorouracil/Mitomycin Regimen. NCI Thesaurus. Code

C156265.

A regimen consisting of fluorouracil and mitomycin that may be used for the treatment of a variety of cancers, such as anal, vulvar, bladder and penile cancer. 